\title{
Benjamín Núñez Vargas y la universidad necesaria para Costa Rica ${ }^{1}$
}

\author{
Benjamín Núñez Vargas and the Necessary University in Costa Rica² \\ Benjamín Núñez Vargas e a universidade necessária para Costa Rica
}

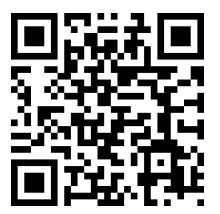

\author{
Martín Omar Aveiro ${ }^{4}$ \\ Universidad Nacional del Sur - CONICET \\ Bahía Blanca, Buenos Aires, Argentina \\ martin.aveiro@uns.edu.ar
}

Recibido 6 de mayo de 2016 • Corregido 1 de julio de 2017 • Aceptado 20 de julio de 2017

Received 6 de mayo de 2016 • Revised 1 de julio de 2017 • Accepted 20 de julio de 2017

Recebido 6 de mayo de 2016 • Revisado 1 de julio de 2017 • Aprovado 20 de julio de 2017

\begin{abstract}
Resumen: El presente trabajo es parte de un proyecto de investigación llevado a cabo en la Universidad Nacional de Cuyo sobre el Humanismo crítico en América Latina en el siglo XX, en su segunda etapa. Inscripto en dos ámbitos disciplinares: la filosofía práctica y la historia de las ideas latinoamericanas. En este caso contribuimos con la revisión y reconstrucción del pensamiento del presbítero Benjamín Núñez Vargas, a quien identificamos como un humanista crítico de orientación cristiana en nuestra América. La atención se concentra en las categorías de reconocimiento y diversidad, a través de sus discursos filosóficos y sociopolíticos con énfasis en sus propuestas para una universidad necesaria en Costa Rica. Se trabajó fundamentalmente sobre la producción discursiva, considerando los discursos como formas de objetivación de la razón práctica. De ahí que apelamos a una revisión bibliográfica y a los aportes de la teoría crítica en cuanto al análisis de las mediaciones sociales, especialmente de las ideologías. Se procedió en tres etapas: exploratoria, analítica y de síntesis.
\end{abstract}

Palabras claves: Humanismo; reconocimiento; diversidad; universidad.

\footnotetext{
${ }^{1}$ Este trabajo es parte del Proyecto de Investigación Sectyp - UNCuyo 2013-2016, radicado en el Instituto de Filosofía Argentina y Americana de la Facultad de Filosofía y Letras de la Universidad Nacional de Cuyo: Reconocimiento y diversidad. Para un humanismo crítico de América Latina en el siglo XX. Segunda etapa. Dir: Dante Ramaglia; Co-dir.: Adriana Arpini (Ramaglia, 2013-2016).

2 This work is part of the Research Project Sectyp - UNCuyo 2013-2016, based in the Institute of Argentine and American Philosophy at the Faculty of Philosophy and Letters of the National University of Cuyo: Recognition and diversity. For a Critical Humanism in Latin America in the Twentieth Century. Second stage.

${ }^{3}$ Este trabalho faz parte do Projeto de Pesquisa Sectyp - UNCuyo 2013-2016, radicado no Instituto de Filosofia Argentina e Americana na Faculdade de Filosofia e Letras da Universidade Nacional de Cuyo: Reconhecimento e diversidade. Para um humanismo crítico na América Latina no século XX. Segunda etapa.

${ }^{4}$ Doctor en Humanidades y Artes con mención en Ciencias de la Educación. Profesor adjunto con dedicación exclusiva, por concurso público, de Teoría Educativa en la Universidad Nacional del Sur. Becario posdoctoral de CONICET en IDICE/UNSJ. Miembro fundador, académico pleno, del Centro de Estudios de Historia de la Educación Argentina Reciente de la Universidad Nacional de Rosario.
} 
doi: http://dx.doi.org/10.15359/ree.21-3.5

URL: http://www.una.ac.cr/educare

CORREO: educare@una.cr

\begin{abstract}
The present work is part of a research project carried out in the National University of Cuyo about the Critic Humanism in Latin America during the second half of the 20th century. It is set in two disciplinary fields: practical philosophy and the history of Latin-American ideas. In this case, we contribute with the revision and reconstruction of Fr. Benjamín Nuñez Vargas' thought whom we consider as critic and humanist, with catholic orientation, in our America. The focus is on categories of recognition and diversity through his philosophical and sociopolitical discourses, with special attention to his proposals for a necessary university in Costa Rica. We worked mainly on the discursive production, considering the discourses as forms of objectification of the practical reason. That is why we had recourse to a bibliographic review and the contributions of the critical theory regarding the analysis of social mediation, especially those of ideologies. We proceed in three steps: exploratory, analytic and of synthesis.
\end{abstract}

Keywords: Humanism; recognition; diversity; university.

Resumo: Este trabalho faz parte de um projeto de pesquisa realizado na Universidade Nacional de Cuyo sobre o humanismo crítico na América Latina no século XX, em sua segunda fase. Inscrito em duas áreas disciplinares: filosofia prática e história das ideias latino-americanas. Neste caso, contribuímos com a revisão e reconstrução do pensamento do padre Benjamín Núñez Vargas, identificado como um humanista crítico e com orientação cristã na nossa América. A atenção está centralizada nas categorias de reconhecimento e diversidade, por meio de seus discursos filosóficos e sociopolíticos enfatizando suas propostas para uma universidade necessária na Costa Rica. Esse trabalho preocupou-se com o discurso, considerando os discursos como formas de objetivação da razão prática. Por isso que apelamos a revisão da literatura e as contribuições da teoria crítica na análise das mediações sociais, especialmente das ideologias. O procedimento se deu em três fases: exploração, análise e síntese.

Palavras-chave: Humanismo; reconhecimento; diversidade; universidade.

\title{
Introducción ${ }^{5}$
}

El humanismo es el primero y el más amplio movimiento intelectual que caracteriza el pensamiento desde el siglo XIV (Arpini, 2015). En la etapa denominada del Renacimiento se llevó adelante una profunda reinterpretación de la civilización cristiana medieval, a partir de una revalorización de la antigüedad grecolatina. En consonancia, el pensador holandés de la orden de los agustinos, Erasmo de Rotterdam (1469-1536), inauguró un humanismo de tipo cristiano que se integraba con la cultura clásica y se oponía al oscurantismo medievalista. En Inglaterra, Erasmo fue protegido por otro intelectual cristiano humanista, Tomás Moro (14781535), quien diseñó en su Utopía, 1516 (Moro, 2003) una sociedad imaginada, sobre una base platónica renacentista, que consistía en la comunidad de bienes.

${ }^{5}$ Agradezco la colaboración del magister, profesor e investigador de la UNA, Andrés Mora Ramírez. 
Así, en los siglos subsiguientes, una serie de sujetos, sin romper con los límites de la confesión católica cristiana, se dieron a la tarea de pensar la sociedad de su tiempo y establecer agudas críticas sobre las falencias que encontraban. Algunos, lo hicieron desde el plano teórico y otros se involucraron en acciones políticas concretas. En América Latina quien funda, de algún modo, esta modalidad encuadrada en una impronta humanista fue el español Fray Bartolomé de las Casas (1474-1566), quien denunció las atrocidades cometidas contras los grupos habitantes originarios de la región y defendió su racionalidad como seres humanos dignos:

En el centro de las preocupaciones se instaló la cuestión de los aborígenes: ¿qué eran estas criaturas?, ¿de dónde venían?, ¿cuál era su naturaleza?, ¿cómo tratarlas?, ¿serían capaces de recibir la fe cristiana y de incorporarse a la vida civilizada?, ¿qué métodos son los adecuados para ese fin, la guerra o la persuasión pacífica? Si se lo analiza desde una perspectiva antropológico-filosófica, se advierte que lo que estaba en tela de juicio era el tema nuclear del humanismo, la dignidad humana. (Arpini, 2015, p. 38)

En adelante, una larga lista de miembros clericales, nacidos en Latinoamérica, fueron protagonistas de hechos políticos significativos en los territorios en los que actuaron. Algunos mantuvieron sus hábitos hasta el fin de sus días, otros los abandonaron en el transcurso de los acontecimientos y muchos de ellos perdieron su vida debido al compromiso asumido en las causas que los envolvieron. Así, podemos mencionar, entre otros, el cura mexicano Miguel Hidalgo y Costilla (1753-1811), el sacerdote salvadoreño Óscar Arnulfo Romero (1917-1980), el obispo brasileño Hélder Pessõa Câmara (1909-1999), el exsacerdote colombiano, muerto en la guerrilla, Camilo Torres Restrepo (1929-1966), el teólogo peruano Gustavo Gutiérrez (1928) o, los argentinos, asesinados, Enrique Angelelli (1923-1976) y Carlos Mugica (1930-1974). Recientemente, se presentó el caso de Fernando Armindo Lugo, quien asumió la presidencia del Paraguay en agosto de 2008 y fue destituido, mediante un polémico juicio político, en el año 2012. Además, actualmente, la máxima autoridad de la iglesia católica es ejercida por el primer papa latinoamericano, Francisco I (Jorge Mario Bergoglio), con un destacado compromiso social.

En esta oportunidad damos a conocer a un clérigo de gran influencia en la historia centroamericana, el presbítero Benjamín Núñez Vargas quien, a su vez, fue precedido por su compatriota Jorge Volio Jiménez (1882-1955). Pusimos el acento en aspectos de su biografía social para, luego, comprender sus propuestas para una universidad necesaria desde el análisis de los discursos y los documentos referidos al tema. Pues, es en la universidad donde se dieron, y aún se dan, las disputas más álgidas entre posiciones pre-humanistas, humanistas clásicas, antihumanistas y humanistas críticas: "La universidad es la institución que difunde en Occidente la idea de que el mundo puede ser explicado racionalmente. La universidad materializa el saber científico e incuba el espíritu laico, vehículo y presupuesto de la nueva ciencia" (Tamayo y Salmorán, 1987, p. 116). Además, la creación de la Universidad Nacional en Costa Rica, que contó con la fundamental participación de Núñez, se plasmó en el marco de una serie de reformas que 
doi: http://dx.doi.org/10.15359/ree.21-3.5

URL: http://www.una.ac.cr/educare

CORREO: educare@una.cr

atravesaron diversos países de América Latina a las que hemos hecho referencia en trabajos anteriores Aveiro (2011). A su vez, damos continuidad a los estudios sobre el intelectual brasileño Darcy Ribeiro, quien fue referencia fundamental para la reforma costarricense (Aveiro, 2015a).

\section{El compromiso social cristiano}

El 15 de mayo de 1891, el papa León XIII publicóla Encíclica Rerum Novarum ${ }^{6}$ donde expuso los fundamentos de la doctrina social de la Iglesia Católica en una clara respuesta al marxismo:"... vio la íntima conexión entre la injusticia, la perturbación del orden social y el crecimiento del socialismo, y propuso la práctica de la justicia como medio para lograr la paz social y vencerlo" (Ferraro, 2009, p. 24). Por tanto, abrió un campo de preocupación y compromiso en los movimientos sociales cristianos por la cuestión obrera. Justamente, luego de ser ordenado sacerdote en 1938, Benjamín Núñez Vargas fundó la Confederación Costarricense del Trabajo Rerum Novarum y en 1943 inició un movimiento con más de setenta sindicatos afines. Incluso llegó a ser ministro de Trabajo con la Junta Fundadora de la Segunda República cuando el Ejército de Liberación Nacional, del que Núñez Vargas era Capellán, se levantó en armas liderados por José Figueres Ferrer frente a los "calderonistas" que al parecer no reconocieron el triunfo electoral de Otilio Ulate Blanco.

Núñez Vargas había nacido en 1915, en medio de una coyuntura de reformas sociales en Costa Rica, pues con la Presidencia de González Flores cobraron relevancia algunos referentes socialistas o anarquistas, entre ellos: el novelista Joaquín García Monge, los poetas Roberto Brenes Mesén y José María Zeledón, la escritora Carmen Lyra, el educador Omar Dengo y el abogado Alfredo González Flores, representantes de la denominada "nueva intelectualidad". El proyecto reformista tuvo una breve duración debido al golpe de Estado de 1917, dirigido por los hermanos Federico y Joaquín Tinoco, que a su vez fueron derrocados por una intensa movilización popular en 1919. Siguió un proceso de radicalización de diversos sectores, mayoritariamente encuadrados en movimientos de mujeres y trabajadores. Incluso un exsacerdote, Jorge Volio, fundó el Partido Reformista que se basaba en la defensa de los intereses de campesinos y obreros. Fue un período en el que se sentaron los pilares para una política de bienestar en el país centroamericano (Molina, 2007-2008).

Por su parte, las dirigencias católicas, inspiradas en la experiencia de Volio y luego de la derrota electoral que sufrieran en las elecciones para presidente de 1928 frente a Cleto González Víquez ${ }^{8}$, comenzaron a sumarse al reclamo por los derechos sociales a fin de atraer el voto popular que disputaban con el comunismo.Y, una década más tarde, lograron tener un candidato presidencial, el

\footnotetext{
${ }^{6}$ En latín significa de las cosas nuevas.

${ }^{7}$ Rafael Ángel Calderón Guardia era candidato a presidente por el Partido Republicano Nacional en las elecciones del 8 de febrero de 1948.

${ }^{8}$ Los católicos llevaban como candidato a presidente a Carlos María Jiménez.
} 
doctor Rafael Ángel Calderón Guardia, quien resultó vencedor en los comicios de 1940. El apoyo de la jerarquía eclesiástica, encabezada por Víctor Manuel Sanabria, a los proyectos de reformas sociales de "calderonistas" era a cambio de derogar las leyes que limitaban la influencia de la Iglesia en el campo educativo (Molina, 2007-2008). Mientras tanto, Sanabria había enviado a Núñez Vargas a los Estados Unidos a estudiar sociología para fundar sindicatos cristianos (Valerín, 2010). De manera que el Pbro. Núñez Vargas, en esos años, pasó por las Universidades de Niágara, Católica y, también, de Columbia, donde conoció a Robert K. Merton y Seymour Martin Lipset. Para entonces, la reforma social de Calderón se había llevado a cabo con la Caja Costarricense de Seguro Social, Garantías Sociales y Código de Trabajo (Molina, 2007-2008) y la fundación de la Universidad de Costa Rica. La Universidad de Costa Rica fue fundada sobre las bases de la primera casa de estudios superiores costarricense, la Universidad de Santo Tomás, que había sido creada en 1843 y cerrada, por razones políticas, en 1890 no logró reabrir sus puertas sino hasta 1941 con la nueva denominación. A su vez, la Universidad provenía de la Casa de Estudios de Santo Tomás que comenzó a funcionar en 1814. Según Cuevas (1995), la Universidad de Costa Rica constituye uno de los importantes hitos de la política cultural del calderonismo. No obstante, un complejo conflicto de intereses contrapuestos, nacionales e internacionales, derivó, luego de las elecciones de 1948, en una guerra civil.

\section{Los aconteceres del ‘48, de cura a capellán y funcionario}

Con el estallido del conflicto armado, comandado por José Figueres Ferrer, el "padrecito" Benjamín Núñez Vargas, munido de alba, estola y una Colt 45 "por cualquier contingencia" (Carreras, s. f.), se sumó al Ejército de Liberación Nacional como capellán. El Ejército de Liberación Nacional, liderado por José Figueres Ferrer, tuvo como objetivo enfrentar la alianza que sostenían calderonistas y comunistas para derrocar al presidente del Partido Republicano, Teodoro Picado Michalski. Más tarde, en la Embajada de México, mantuvo una conversación con el líder comunista Manuel Mora Valverde para acercar posiciones con José Figueres Ferrer. Con lo cual se arribó al "Pacto de Ochomogo" y fue el mismo Núñez Vargas quien presentó al Cuerpo Diplomático, reunido al efecto, los acuerdos entre Mora y Figueres. De esta manera concluyó la guerra civil a través del denominado "Pacto de la Embajada de México" (Contreras, 2008).

Inmediatamente, se conformó la Junta Fundadora de la Segunda República, que integró Núñez Vargas, y que gobernó el país durante 18 meses. En ese tiempo se tomaron medidas de corte benefactor (Delgado, 2008): nacionalización bancaria, la creación del ICE -Instituto Costarricense de Electricidad-, abolición del Ejército, aprobación del sufragio femenino, derogación de disposiciones contra la ciudadanía afrodescendiente, entre otras. Además, se convocó a una Asamblea Constituyente que proclamó una nueva Constitución Política de la República, el 8 de noviembre de 1949, y que es la que actualmente rige con reiteradas reformas en Costa Rica. Esta, con respecto a la problemática educativa, amplió lo dispuesto por la Constitución de 1871 que se limitaba a tan solo dos artículos y lo reemplazó por un capítulo llamado "Educación y Cultura" donde se establecía la responsabilidad del Estado, cuestión que generó arduos y 
doi: http://dx.doi.org/10.15359/ree.21-3.5

URL: http://www.una.ac.cr/educare

CORREO: educare@una.cr

acalorados debates con los sectores católicos representados por Monseñor Sanabria. También, según Quesada (2003), se dispuso para la única Universidad existente hasta ese momento su independencia para el desempeño de funciones, la dotación de patrimonio y financiamiento por parte del Estado y la libertad de cátedra como principio fundamental de la enseñanza.

... el centro de su preocupación es la educación y, dentro de ella, la Universidad de Costa Rica. Al revisarse el capítulo se puede observar claramente que más del $50 \%$ del articulado se refiere específicamente a la educación, y un $25 \%$ exclusivamente a la Universidad. (Cuevas, 1995, p. 30)

Enseguida se traspasó el primer mando a Otilio Ulate Blanco, quien ejerció la Presidencia hasta 1953. En tanto, Figueres Ferrer organizaba el Partido Liberación Nacional con el cual fue elegido por el voto popular para reemplazar a Ulate Blanco. "Don Pepe", como le llamaban a Figueres Ferrer, nombró al padre Benjamín Núñez Vargas representante permanente ante las Naciones Unidas, en donde tuvo una participación destacada, sobre todo en lo referente a la independencia de Argelia y en las discusiones relativas al derrocamiento de Jacobo Arbenz. En respuesta, elaboraron junto a Figueres Ferrer la política de no reconocimiento hacia gobiernos militares surgidos de golpes de Estado. También con ese cargo tuvo la posibilidad de visitar Israel y estrechar lazos con David Ben Gurion (1886-1973), uno de los principales mentores de aquel Estado sobre el que declaró su independencia. Para N. Lijtmaer (comunicación personal, 11 de noviembre de 2015), David Ben Gurion pertenecía a las líneas sionistas socialistas. Sin embargo, cabe aquí la siguiente aclaración:

El movimiento y las corrientes sionistas se caracterizan por asumir varias ideologías, y cada una de ellas hoy conforma partidos en el Estado de Israel. Por ejemplo, el sionismo político relacionado con Teodoro Herzl impulsa el establecimiento de un Estado Judío soberano e independiente. El sionismo práctico pone el énfasis en los medios prácticos para la consecución de los objetivos sionistas tales comola aliá(inmigración), el asentamiento ruralylasinstituciones educacionales. El sionismo sintético tuvo su principal portavoz en Jaim Weizmann. El sionismo religioso se basa en una fusión de la religión y la nacionalidad judía. El sionismo espiritual es una tendencia en el pensamiento judío moderno defendida por Ajad Haam. El sionismo socialista tiene como fundador a Najman Syrkin y aspira a establecer un Estado Judío en el que considere al judaísmo como una nacionalidad, y en el que las bases del Estado estén identificadas con el socialismo, es decir, el trabajo comunal. El sionismo revisionista actúa en pro de un Estado Judío en ambas márgenes del río Jordán. (Kaufmann, Lijtmaer \& Mauri, 2008, p. 93) ${ }^{9}$

\footnotetext{
${ }^{9}$ Hecha esta aclaración debemos mencionar que el movimiento sionista, en todas sus vertientes y corrientes, tiene como base la expansión sobre el territorio palestino y la expulsión violenta del pueblo palestino con ciertas características genocidas. Ver el documental facilitado por N. Lijtmaer (comunicación personal, 12 de noviembre de 2015): https://www.youtube.com/watch?v=ZeR1x4TZ280
} 
Terminada su misión en la ONU regresó a sus actividades parroquiales y universitarias en Costa Rica. Asimismo, fundó un instituto de formación política para el Partido de Liberación Nacional, inspirado en la experiencia del laborismo inglés, que luego se amplió por la ayuda internacional y llegó a tener su propio órgano de difusión, la Revista Combate, dirigida por Luis Alberto Monge. En aquella Revista el sacerdote publicó un artículo denominado "La función social de la religión", y hay quienes lo llamaron el hombre del pre-agiornamento (Carreras, s. f.).

Es preciso recordar que eran momentos en que la Iglesia Católica se preparaba para su último gran Concilio, el Vaticano II. Y que, a pesar de la prohibición de sus lecturas, por parte de Juan XXIII, los escritos del jesuita francés Pierre Teilhard de Chardin (1881-1951) estuvieron presentes en gran parte de las conclusiones de aquel cónclave cristiano. Por cierto, Teilhard de Chardin decía algo que bien puede ser aplicado a Núñez (citado por Núñez de Castro, s. f.): "Por educación y formación intelectual, pertenezco a los hijos del Cielo. Pero por temperamento y por estudios profesionales soy un hijo de la Tierra" (p. 21). Así pues, tanto el teólogo y antropólogo nacido en Francia como el italiano Giovanni Batista Montini, quien llevó a término el Concilio Vaticano II con el nombre de Paulo VI, fueron claras referencias en la orientación espiritual y misional de Núñez Vargas. También, más tarde, lo fue el cura Jorge Camilo Torres Restrepo al que envió una misiva al poco tiempo de que aquel abandonara los hábitos para integrarse a la guerrilla junto al Ejército de Liberación Nacional colombiano en 1965 (Chase, 2013).

\section{Manifiesto democrático para una revolución social}

Con la llegada a la Presidencia de Francisco J. Orlich, el padre Núñez Vargas asumió la dirección del Instituto Nacional de Vivienda y Urbanismo donde se desempeñó algunos años. Luego se dedicó a finalizar su carrera doctoral en la Universidad Católica de Washington D. C. con una investigación sociológica sobre la clase profesional de Costa Rica. Cuando el candidato del Partido de Liberación Nacional, Daniel Oduber, perdió las elecciones presidenciales, frente a una coalición de partidos conservadores encabezada por José Joaquín Trejos Fernández, Núñez Vargas se mantuvo dedicado a sus actividades académicas como profesor de Sociología en la Universidad de Costa Rica, que era la más alta exponente de la cultura del país (Carreras, s. f.; Cuevas, 1995). Si bien, sostiene Molina (2007-2008), la universidad se caracterizó por un profundo conservadurismo académico y cultural, no escapó a las vicisitudes de la década del sesenta:

Los ecos de París de los campus universitarios americanos y de los rincones de las montañas latinoamericanas se hacen sentir en nuestro país. En Costa Rica el ímpetu y el desasosiego se apoderan de muchos sectores y surge el cuestionamiento en las mentes jóvenes, intelectuales y dirigentes del partido y sindicales. Hay una demanda por una revalorización ideológica y nuevos rumbos para enfrentar el aburguesamiento del partido. (Carreras, s. f., Grupo de Patio de Agua, párr. 3) 
doi: http://dx.doi.org/10.15359/ree.21-3.5

URL: http://www.una.ac.cr/educare

CORREO: educare@una.cr

La demandajuvenil por una renovación ideológicay cultural del tradicional funcionamiento social y político llevó al padre Núñez Vargas a reunir en su casa, en Patio de Agua de Coronado, a un grupo de compañeros que se dedicaron a pensar una serie de principios para la acción política del Partido de Liberación Nacional (Carreras, s. f.). De estas reuniones surgió el Manifiesto democrático para una revolución social ${ }^{10}$, que recogía "un pensamiento profundamente humanista" preocupado por "restaurar, en las banderas de su partido, el espíritu inicial de consagración al servicio del pueblo" (Arauz et al., 1968, p. 3). Tenía como objetivo "un examen de conciencia, una rectificación de la conducta, un retorno a la ruta inicial y una voluntad de misión histórica" (Arauz et al., 1968, p. 3). No se cerraba en ninguna doctrina, sino que aprende de todas lo mejor para servir a la causa de una "revolución en libertad" $y$ "ofrece un pensamiento político costarriqueñista para liberar al pueblo costarricense" (Arauz et al., 1968, p. 3). El documento comienza con un enunciado de principios para después abordar una serie de orientaciones programáticas específicas, los instrumentos de acción y los requisitos éticos. Estas orientaciones programáticas se dividían en: la propiedad, la educación, la salud, el trabajo, seguridad social, política de población, política agraria, política tributaria, política urbanista, vivienda, medios de comunicación colectiva, transportes, crédito e inversión, desarrollo económico, la financiación del desarrollo, integración de la economía nacional, el comercio internacional y el desarrollo, el Estado y sus órganos, reforma municipal, seguridad pública y civilidad, relaciones internacionales, factores religiosos.

El Manifiesto democrático para una revolución social entendemos, más allá de lo dicho en el párrafo anterior, se situaba teóricamente, por un lado, en las conclusiones del Concilio Vaticano II. Son notorias las referencias a la Constitución Guaudium et Spes, además de los postulados de Paulo VI, sobre todo en la exhortación apostólica Evangelii Nuntiandi y la encíclica Populorum Progressio. Y, por otro lado, en un desarrollismo económico de corte nacional con una fuerte intervención del Estado. En realidad, ambas posturas son coincidentes, pues Paulo VI repetía en

\footnotetext{
${ }^{10}$ El Manifiesto fue firmado el 6 de enero de 1968 por: Armando Arauz Aguilar, Antonio Arroyo Alfaro, Isaac F. Azofeifa Bolaños, Enrique Azofeifa Víquez, José R. Acuña Montenegro, Rodrigo Barahona Israel, Fernando Berrocal Soto, Jorge Blanco Campos, Francisco Calderón Solanos, Alfonso Carro Zúñiga, Rodrigo Carreras Jiménez, Jorge Mario Castro Vegas, José Rafael Cordero Croceri, Fernando Coto Chacón, Mario Carvajal Herrera, Mario Charpentier Gamboa, Juan José Echeverría Brealy, Carlos Luis Fernández Fallas, Johnny Fernández Saborío, Rodrigo Fernández Vaázquez, Eugenio Fonseca Tortós, Rosita Girbenstein de Mayer, Paulino González Villalobos, Claudio Gutierrez Carranza, Rodolfo Gutiérrez Carranza, Jorge Gutiérrez Gutiérrez, Rodrigo Gutiérrez Sáenz, María del Carmen Gutiérrez de Chittenden, Gonzálo Jiménez Chaves, Alvaro Jiménez Zavaleta, Matilde Marín de Soto, Ciro Montero Guevara, Francisco Morales Hernández, Francisco Morales Morales, Luis Alberto Monge Alvarez, Carl E. Neil Neil, Marco Nerín Hidalgo Badilla, Benjamín Núñez Vargas, Enrique Obregón Valverde, León Pacheco Solano, Carlos Pascua Zuñiga, Carlos Luis Rodríguez Hernández, Manuel Rojas Bolaños, Milton Ruiz Guzmán, Carlos Salazar Vargas, Jorge Solano Chacón, Rodolfo Solano Orfila, Enrique Soto Borbón, Gerardo Trejos Salas, Francisco Tacsam Lam, Carlos Villanueva Badilla, Jorge Luis Villanueva Badilla, José Manuel Villalobos Villalobos, Fernándo Volio Jiménez, Rómulo Valerio Rodríguez, José Ambrosio Villegas Rodríguez, José Luis Vega Carballo y Jorge Urbina Ortega.
}

8

Martín Omar Aveiro

Los artículos de la Revista Electrónica Educare del Centro de Investigación y Docencia en Educación de la Universidad Nacional, Costa Rica, se comparten bajo términos de la Licencia Creative Commons: Reconocimiento, No Comercial, Sin Obra Derivada 3.0 Costa Rica. Las autorizaciones adicionales a las aquí delimitadas se pueden obtener en el correo: educare@una.cr 
Populorum Progressio un mandato conciliar de la Guaudium et Spes: "Los pueblos ya desarrollados tienen la obligación gravísima de ayudar a los países en vías de desarrollo" (Pablo VI, Deber de solidaridad, 1967, párr. 1). En el documento costarricense se aceptaba la ayuda internacional para financiar el desarrollo, "en forma transitoria y subsidiaria", pero "sujetas a condiciones de dignidad y conveniencias nacionales" (Arauz et al., 1968, p. 32). Aun así, no aparecen en el texto las críticas hacia el desarrollismo que se venía produciendo desde las teorías de la dependencia y que sirvió de matriz para el despliegue de la Teología de la Liberación:

La situación de endeudamiento, pobreza y dependencia en la que se hallaba Latinoamérica provocó el surgimiento de voces que invitaban a comprometerse en la superación de la dependencia y conseguir la liberación de los pueblos del llamado Tercer Mundo. Este empeño liberador se va a ir gestando de formas distintas pero convergentes en diferentes ámbitos de la realidad social y cultural ... . En esta labor de preparación y de contagio, tenemos que referirnos a una matriz económica, la teoría de la dependencia; una matriz pedagógica, la pedagogía del oprimido de Paulo Freire; una matriz religiosa, la teología de la liberación; una matriz artística y literaria, el muralismo mexicano y el boom de la novela latinoamericana; y una matriz filosófica, el trabajo precursor de Leopoldo Zea y de Augusto Salazar Bondy. (Beorlegui, 2004, p. 677)

Teorías de las cuales se diferenció Núñez por su manifiesto apoyo a Palestina frente a la existencia del Estado de Israel (Núñez, 1992). Ahora bien, a pesar de las limitaciones del Manifiesto y de su explícito moralismo, que iba de la mano con la cruzada por el "rearme moral" que proclamaba José Figueres Ferrer (Figuerres, 2000), sirvió de base para la renovación del Partido de Liberación Nacional que logró un contundente triunfo electoral en 1970 (Carreras, s. f.). Con Figueres Ferrer nuevamente en la Presidencia, Benjamín Núñez Vargas fue nombrado Embajador Extraordinario y Plenipotenciario en Jerusalén y Embajador concurrente en Bucarest. En esa función logró consolidar los vínculos entre Costa Rica e Israel y defendió, una vez más, su existencia como Estado frente a los intereses árabes y la influencia comunista (Carreras, s. f.). Figueres Ferrer había definido su alineamiento con el bloque occidental contra la invasión de la Unión Soviética que, entendía, Costa Rica era la primera víctima de 1940 a 1948 (Figueres, 2000) ${ }^{11}$. Razón por la cual, más tarde, se alineó con los Estados Unidos en la "Alianza para el

\footnotetext{
${ }^{11}$ De acuerdo al [sic] artículo 98 de la Constitución, se prohibió, en 1950, el Partido Vanguardia Popular, lo que se extendió a la "... formación y funcionamiento de toda organización política de filiación y extracción comunista, cualquiera que sea la denominación que adopte ..." (Colección de Leyes y Decretos; Asamblea Legislativa de Costa Rica; Nr. 1191; agosto 1 de 1950), y más tarde, durante el primer período presidencial de José Figueres Ferrer, a “... la publicación, importación, venta, exhibición o circulación de los folletos, revistas, libros u otros escritos, impresos o no, y de los grabados, figuras, estampas, que fueran: a) de ideología o tendencia comunistas ... (op. cit.; Decreto Nr. 37 del Poder Ejecutivo del 21 de julio de 1953) (citado por Cuevas, 1995, p. 66).
} 
doi: http://dx.doi.org/10.15359/ree.21-3.5

URL: http://www.una.ac.cr/educare

CORREO: educare@una.cr

Progreso" - ALPRO - y fustigó la aventura comunista cubana por dos motivos: su carácter totalitario y por "haberse pasado al lado del enemigo en el campo de la Guerra Fría", actitud que juzgaba de "infantilismo". Decía al respecto: "Con ligereza nos acusan a todos de estar al servicio del imperialismo norteamericano, y solamente nos proponen, como alternativa para salirnos del pecado, que nos pongamos al servicio del imperialismo ruso" (Figueres, 2000, p. 199).

Todos estos procesos que se dan en Costa Rica están signados por dos eventos de carácter político: la Revolución Cubana y la Alianza para el Progreso. El impacto de la primera es importante en la medida en que lleva al surgimiento de grupos de artistas e intelectuales que se identifican con ella, constituyéndose en grupos contestatarios frente a la cultura "oficial" impulsada por el Estado. Esta última se encuentra bajo la égida de los "hombres de letras" del Partido Liberación Nacional (PLN), que se desplaza a la derecha y abraza la Alianza para el Progreso como opción ideológica. (Cuevas, 1995, pp. 72-73)

Con todo, la combinación de desarrollismo, políticas económicas proteccionistas y socialdemocracia instalada en Costa Rica desde la década del '50 generó una prosperidad sostenida en relación a la región centroamericana:

La relevancia del crecimiento y diversificación del Estado se expresa, por ejemplo, en el número de instituciones creadas: entre 1950 y 1970 más de 50, 22 de ellas con objetivos sociales (principalmente en salud y educación); ya en 1980 las instituciones sociales sumaban 126. La inversión estatal pasó de ser el 9\% del PIB en 1950 al 15\% en 1970. En los años 70, se crearon el IMAS (pobreza extrema, grupos marginados), Asignaciones Familiares (nutrición, vivienda), el FODESAF, Fondo de Desarrollo Social y Asistencia a la Familia (actividades productivas, salud, vivienda). Para intentar una evaluación centralizada de programas sociales, se creó en 1974 el Sistema de Planificación Nacional, con el MIDEPLAN.

Dos aspectos merecen la pena comentar: el gasto social y la conciliación social. El presupuesto nacional destinado a los servicios sociales, especialmente salud y educación, se incrementó sistemáticamente entre 1950 y 1978. Todos los indicadores sociales progresaron. Se trataba del compromiso estatal con el bienestar de la población: el Estado benefactor. (Ruiz, 2001, p. 31)

\section{La fecunda tarea de construir una Universidad necesaria para Costa Rica}

Mientras la Alianza para el Progreso, a comienzo de los años 70, mostraba sus falencias e incluso su fracaso, comenzaba a gestarse la segunda Universidad costarricense. Decía el dominicano Bosch (1971): 
No hay soluciones extranjeras. Esas soluciones han fracasado completamente. Este fracaso fue reconocido por el presidente Nixon cuando al hablar en la sede de la Organización de los Estados Americanos (OEA) en Washington, el 15 de abril [de 1969], en ocasión de la celebración del Día de las Américas, dijo que el crecimiento de la economía latinoamericana no era más grande que cuando se inició ocho años atrás el programa de la Alianza para el Progreso. (p. 18)

Así, la complejidad de la década precedente, como en otras partes de Latinoamérica, generó una fusión de propuestas provenientes del desarrollismo con otras de tinte claramente radicalizadas frente a las potencias hegemónicas mundiales:

... sectores de estudiantes y profesores empezaron a rebelarse contra el orden establecido, proceso que culminó en abril de 1970, cuando miles de jóvenes de secundaria y universitarios apedrearon la Asamblea Legislativa a raíz de las concesiones otorgadas por los diputados a la trasnacional ALCOA. (Molina, 2007-2008, p. 267)

Incluso los grupos más conservadores que enseñaban en la Universidad de Costa Rica situaban sus esperanzas en que una nueva institución universitaria restablecería el orden perdido, cuestión que no ocurrió, pues la Universidad Nacional nació con el propósito de contraer un "compromiso efectivo con su realidad nacional" (Núñez, 1974, p. 9). Quien asumió esta tarea, luego de su regreso de Jerusalén, fue el padre Benjamín Núñez Vargas junto a una Comisión Ad Hoc establecida por la Ley N. ${ }^{\circ}$ 5.182, del 15 de febrero de 1973. Prácticamente al mismo tiempo, Ribeiro (1973) publicaba La Universidad Nueva, un proyecto donde expresaba su descontento con la universidad tal cual es:

Descontento con su connivencia con las fuerzas responsables por la dependencia y el atraso de América Latina. Descontento con la mediocridad de su desempeño cultural y científico y, más aún, con su irresponsabilidad frente a los problemas de los pueblos que la mantienen. (p. 5)

Recordemos que el brasileño permanecía exiliado después del golpe de Estado que azotó Brasil en 1964 y que, entre los motivos de su expatriación, se encontraban sus iniciativas por crear una universidad seria, democrática y comprometida con la realidad de su país. En su largo periplo por diferentes territorios del continente, Ribeiro visitó Costa Rica (Araya, 1990; Núñez, 1974). Su pensamiento y planteamientos concretos estimularon a continuar con el esfuerzo para "la construcción de la Universidad Nacional como una universidad nueva, no sólo en un sentido cronológico, sino más bien en su sentido más profundo"(Núñez, 1974, p. 8). Conjuntamente algunas universidades latinoamericanas vivían procesos de transformación, entre ellas: las peruanas, venezolanas y argentinas, aunque cada una en la diversidad particular de entramados socio-políticos que les daban cierta singularidad y lo mismo podemos decir del emprendimiento costarricense. Todas las experiencias, consustanciadas con la época, cuestionaban el verticalismo en la enseñanza y la desvinculación de las casas de estudios con las necesidades sociales, pero cada una lo hacía a su 
doi: http://dx.doi.org/10.15359/ree.21-3.5

URL: http://www.una.ac.cr/educare

CORREO: educare@una.cr

modo. Así, en Perú se pensaba un modelo que acompañara los cambios que movilizaba el gobierno de Juan Velasco Alvarado; en Venezuela la juventud se oponía al burocratismo y al autoritarismo pedagógico y, en Argentina, con el retorno democrático del peronismo a la Presidencia, se pretendía una superación de las antinomias que desde la"Reforma de 1918"se habían instalado en los ámbitos académicos ${ }^{12}$. La originalidad del caso costarricense estuvo dada porque fueron encaradas por un sacerdote con ideas de avanzada que pone en funcionamiento la Universidad en relación con una sociedad concreta (Núñez, 1974), pues para Ribeiro (1973):

Entre este modelo ideal y cualquier proyecto concreto, aun el que más se aproxime a él, existirá siempre la distancia que separa las abstracciones de las cosas. El desafío que enfrentarán los que acepten este modelo como una meta es, por lo tanto, el de cubrir de carne, piel, sangre y pigmento a sus huesos descarnados para que llegue a existir un día en el mundo de las cosas, como la Universidad que corresponde a las necesidades de un pueblo en un momento dado de su existencia histórica. (p. 157)

Es decir, que se buscaba adecuarla a la realidad nacional para definir los intereses hacia los cuales servir, de acuerdo con una racionalidad instrumental, categoría que nos remite al pragmatismo de impronta norteamericana. Pues, debemos mencionar que tanto Núñez Vargas como Darcy Ribeiro recibieron el influjo de las teorías sociológicas y antropológicas que predominaban en los Estados Unidos. El primero por los estudios que había realizado en el país del norte y el segundo por la influencia de aquellos enfoques en la Escuela de Sociología y Política de São Paulo, donde Ribeiro se graduó de antropólogo. Pero, además, por la cercanía que mantuvo Ribeiro con Anísio Teixeira, uno de los pioneros de la educación nueva brasilera, quien a su vez se había formado con el pedagogo estadounidense John Dewey (Aveiro, 2013) y cuya obra, suponemos, debe haber conocido Núñez Vargas en su paso por Columbia ${ }^{13}$.

Por su parte, la Universidad Nacional -UNA- fue creada en el marco de las iniciativas del Partido de Liberación Nacional que ocupó el gobierno entre 1970 y 1978 -José Figueres Ferrer (1970-1974) y Daniel Oduber (1974-1978)-, donde se llevaron hasta las últimas consecuencias el planteamiento reformista que se originó en los años cuarenta y cincuenta, lo cual conlleva la creación de nuevas instituciones públicas (Cuevas, 1995). Así, la UNA recoge la herencia de la Escuela Normal, donde tuvo una destacada participación el pedagogo Omar Dengo (18881928), y de la Escuela Normal Superior, la cual fue creada por la presidencia de Alfredo González

\footnotetext{
12 Podemos caracterizar las antinomias, para simplificar, de la siguiente manera: reformistas-antirreformistas, peronistas-antiperonistas, modernizadores-oscurantistas. Cabe aclarar que ninguna de estas denominaciones se agota en sí misma, dado que en cada una podemos desglosar posicionamientos, diferencias y contrastes.
}

${ }^{13}$ Sería interesante un estudio específico al respecto. 
Flores (1914-1917), en la ciudad de Heredia, para centralizar la formación docente y fue, hasta la creación de la Universidad de Costa Rica, la principal institución generadora del intelecto costarricense. Por su parte, la Escuela Normal Superior se creó, mediante un decreto del Poder Ejecutivo, en 1967, para responder a la creciente demanda por la formación de profesorado para la enseñanza media y fue aprobada por Ley en 1968 ante la oposición de la Universidad de Costa Rica (Rivera, 2012). Entonces, frente al requerimiento por una universidad pedagógica y el reclamo de ampliación del acceso a diversos sectores sociales, debido al importante crecimiento demográfico, expresado en el Tercer Congreso Universitario (1971-1972), el ministro de Educación Pública, Prof. Uladislao Gámez Solano, presentó el proyecto de Ley de Creación de la Universidad Nacional en setiembre de 1972 (Rivera, 2012).

A pesar de la arraigada oposición de la Universidad de Costa Rica, el proyecto de creación de la UNA en la ciudad de Heredia fue aprobado por unanimidad en la Asamblea Legislativa. De este modo, desaparecieron las escuelas normales y la formación docente, incluyendo la primaria y preescolar, fue elevada al rango universitario (Rivera, 2012). Esto decía el flamante primer rector de la UNA, Benjamín Núñez Vargas, al asumir funciones el 14 de marzo de 1973:

Aquí en Heredia se encendió la luz de la docencia nacional cuando en 1915 se abrió en esta ciudad la primera Escuela Normal ... La ciudad de Heredia puede enorgullecerse de su tradición universitaria, pues antes de que se iniciara la Universidad de Costa Rica, Heredia era ya sede del pensamiento humanista que irradiaba inspiración en todos los contornos de nuestra patria.

... Venimos a forjar una nueva Universidad porque el pueblo costarricense necesita de una academia más que interprete sus aspiraciones, investigue sus realidades, señale respuestas a sus problemas en el campo de la ciencia y del humanismo, cooperando así con quienes, en los diferentes campos de la vida nacional, están llamados a crear un mundo mejor para todo el hombre costarricense y para todos los hombres de nuestra patria. (Núñez, citado por Rivera, 2012, p. 67)

Benjamín Núñez Vargas permaneció en el rectorado de la UNA entre 1973 y 1976, a pesar de que hacia 1974 comenzó a manifestarse una crisis económica que se agudizó a finales de la década con una creciente inflación y devaluación de la moneda (Cuevas, 1995), situación que asumió el rector entrante en 1977, Alfio Piva Mesén, y que derivó en ciertas limitaciones presupuestarias de la institución (UNA 40 años. Educación superior para el bien común, 2013). De todos modos, sus lineamientos principales opuestos a la universidad tradicional quedaron plasmados en su Estatuto Orgánico, proclamado en 1976 por Núñez Vargas, donde se estableció 
doi: http://dx.doi.org/10.15359/ree.21-3.5

URL: http://www.una.ac.cr/educare

CORREO: educare@una.cr

una participación amplia de los sectores populares (Araya, 1990). De ahí que cobra sentido la afirmación hecha sobre él: "Cuando siente que su obra está ya consolidada se jubila como un profesor universitario y deja la rectoría confiado que llegará a puerto seguro" (Carreras, s. f., Universidad Nacional, párr. 2).

Concluida su labor en la UNA regresa a la embajada de Jerusalén y a una intensa actividad diplomática. Cuando accede a la presidencia Luis Alberto Monge Álvarez en 1982, es nombrado representante permanente de su país ante la UNESCO. A su retorno, desde 1985, trabajó junto a José Figueres Ferrer en el Centro de Estudios Centroamericanos y Caribeños. Colaboró con este en la redacción de El Espíritu del 48, publicado por la Editorial Costa Rica en 1987 y, también, en su propio libro: Del Volcán Irazú al Monte Sión, publicado por EUNA en 1992 (Carreras, s. f.). Al cumplirse el décimo aniversario de la UNA, decía el Dr. Núñez en su discurso: “Tengo fe en la Universidad Nacional... pondremos en ella lo mejor del corazón y de la inteligencia... En ella será bello trabajar, bello vivir y, si es necesario, bello morir" (La Prensa Libre, 2015, párr. 8). Al año siguiente fallecía en la ciudad de San José "el cura amigo" como lo llamó uno de sus hijos y biógrafo, Rodrigo Xavier Carrera Jiménez, quien hasta 2015 era el embajador Extraordinario y Plenipotenciario de Costa Rica en Israel al igual que su padre (Arbeláez, s. f.).

\section{Conclusiones}

El problema judío es central en el pensamiento político, académico y teológico en la concepción cristiana humanista de Benjamín Núñez Vargas. Sus reflexiones como seminarista lo llevaron a librarse del dogmatismo y de la "teología del repudio"14 para abrirse al conocimiento desprejuiciado, base necesaria para el conocimiento científico. Cuestión que se complementaría cuando Monseñor Sanabria lo envía a los Estados Unidos para formarse en las ciencias sociales, en los momentos en que comenzaba la Segunda Guerra Mundial (Núñez, 1992). En las universidades norteamericanas conoció autores de la talla de León Bloy, Nicolás Berdyaev o Jacques Maritain, católico de esposa judía.

Así, sus reflexiones divagaban entre lo religioso, lo científico y lo político, desde donde asumía lo académico. Se opuso a las corrientes católicas antisemitas y ultramontanas como la del francés Charles Mourras. Aunque, sus actividades diplomáticas lo llevaron al extremo opuesto en la defensa exacerbada del sionismo en el plano internacional frente a los países árabes y al tercermundismo, lo cual tiñe en cierto sentido los comentarios anteriores. De todos

\footnotetext{
14 “La 'teología del repudio' establece su tesis fundamental en éstos términos: al presentarse Jesús de Nazareth reclamando para sí ese elevado título de Mesías y de Hijo de Dios, el pueblo judío, su pueblo, no le reconoció como tal, sino que, por el contrario, le crucificó. La 'teología del repudio' pretende que, a causa de esa actitud y ese 'crimen', Dios rescindió la alianza con el pueblo judío. El que había sido Pueblo Escogido, pasó a ser el pueblo maldito y proscrito por Dios a causa de su abominable crimen. Ese crimen se conoce en la historia como el DEICIDIO"(Núñez, 1992, p. 17).
} 
modos, un hecho lo conmovió profundamente como sacerdote y estudiante de ciencias sociales en los Estados Unidos: la indiferencia del mundo, sobre todo cristiano, y su ignorancia ante el asesinato de seis millones de judíos en el Holocausto o Shoah ${ }^{15}$. Y se preguntaba:

¿Cómo fue que yo, siendo universitario, intelectual en cierne, que debiera estar alerta a lo que le pasara al hombre y a la civilización en que yo vivía, que yo siendo sacerdote que debiera estar atento a la responsabilidad de la Iglesia sobre la auténtica realización del cristianismo frente a la suerte de todos los grupos humanos, pude haber estado ignorando el genocidio del pueblo judío, que se estaba consumando, y, por tanto, totalmente indiferente a sus horrores? (Núñez, 1992, p. 106)

Esta pregunta, tal vez, determinó luego su mirada sobre la cuestión universitaria, dado que la universidad necesaria no podía estar ajena a los problemas del planeta y de la sociedad en la cual se encontraba inserta. Inclusive, uno de los modelos de referencia para la educación superior lo encontró en el estado de Israel, sobre todo en la Universidad Hebrea de Jerusalén, por hacer de la ciencia y la tecnología, inspiradas en la reflexión filosófico-humanista, la clave de su desarrollo integral (Núñez, 1992). En esa Casa de Estudios llegó a ser invitado a participar de la cátedra sobre Problemas Latinoamericanos (Núñez, 1992). Y, al igual que su gobierno hacia la década del setenta, se inclinaba por enmarcar la organización política entre la eficiencia del capitalismo y la solidaridad del socialismo. Según Núñez (1992), el sionismo es un movimiento de liberación que combina la afirmación de la libertad con la justicia social, cuestión que se pretendía repetir, para la misma época, en la socialdemocracia costarricense cuando se creaba la UNA (Núñez, 1992).

\footnotetext{
${ }^{15}$ Primo Levi es el primero que rechaza el término de Holocausto, ya que semánticamente alude a un sacrificio divino. Al respecto, dice Antonio Muñoz Molina, comentarista de la obra de Levi: 'Le desagradaba la palabra «Holocausto» porque veía en ella una tentativa de encontrar un sentido de sacrificio sublime o de pasión religiosa a lo que no había sido más que un proyecto político de sometimiento y destrucción de los seres humanos'. En P. Levi (2005) Trilogía de Auschwitz. Barcelona: Océano. Parece ser que quien acuña el término Holocausto es Elie Wiesel, priosionero de Auschwitz y escritor del libro testimonial La nuit, aunque luego con el tiempo se habría arrepentido de haberlo puesto en circulación. En efecto, este término tiene un origen semántico que alude al sacrificio en un marco de entrega de causas sagradas, particularmente en las matanzas medievales de judíos. Giorgio Agamben lleva a cabo el rastreo de esta expresión y al respecto dice: 'En el caso del término «holocausto», por el contrario, establece una conexión, aunque sea lejana, entre Auschwitz y el olha bíblico, entre la muerte en las cámaras de gas y "la entrega total a motivos sagrados superiores' no puede dejar de sonar como una burla. No sólo el término contiene una equiparación inaceptable entre hornos crematorios y altares, sino que recoge una herencia semántica que tiene desde el inicio una colaboración antijudía. (...) Quien continúa aplicáncolo da prueba de ignorancia o de insensibilidad (o de una y otra a la vez)'. En G. Agamben (2005) Lo que queda de Auschtwitz. El archivo y el testigo. Valencia: Pre-textos, p. 31 (Levi, citado en Avila, 2015, p. 101-102). En cambio, siguiendo con Avila (2015), es más preciso hablar de Shoah que significa devastación o catástrofe.
} 
doi: http://dx.doi.org/10.15359/ree.21-3.5

URL: http://www.una.ac.cr/educare

CORREO: educare@una.cr

En tanto, los años setenta recibían las transformaciones sociales de la década anterior, además del impacto generado por el inédito crecimiento demográfico mundial que en América Latina cobraba una intensidad particular (Aveiro, 2015b). Este fenómeno, según Roig (1998), determina toda la problemática universitaria, tanto en su estructura como en su finalidad pedagógica, social y científica. Y es con este panorama que se encontró Núñez cuando fue desginado para intervenir en la creación de la nueva universidad costarricense. A su vez, la Universidad Nacional recibió la herencia de una educación crítica, comprometida y democrática de la Escuela Normal y de la Escuela Normal Superior (Araya, 1994). También, pretendió aplicar el prototipo universitario que propugnaba el pensador brasileño, Darcy Ribeiro, para América Latina en orden a contribuir al desarrollo económico y social del país (Araya, 1994).

Se le dio una estructura organizativa compleja aunque articulada entre centros, facultades e institutos. Los centros se proyectan sobre toda la vida univesitaria a diferencia de las facultades que lo hacen sobre campos específicos del conocimiento. Por su parte, los institutos cultivan la investigación interdisciplinaria en saberes básicos. De este modo, se combina en un mismo rango jerárquico la docencia, la investigación y la extensión (Araya, 1994). Asimismo, se orientó principalmente a satisfacer la demanda de educación superior de los sectores de menores recursos y en cuatro años pasó de 3.174 a 10.119 estudiantes, que no fue del todo acompañado por recursos financieros suficientes (Araya, 1994).

De este modo, la universidad de los sectores pobres o de los grupos refugiados extranjeros (guatemaltecos, chilenos, nicaragüenses, salvadoreños y otros) (Quesada, 1993), como llegaron a llamarle, es actualmente la referencia nostálgica y el arquetipo de una parte de la intelectualidad costarricense. País centroamericano que, si bien no atravesó las feroces dictaduras de la región latinoamericana, fue arrasado por las políticas neoliberales y el desguaze de las instituciones financiadas por el Estado, entre ellas las universidades. Por eso, la importancia de reconocer la obra del Pbro. Benjamín Núñez Vargas, quien con su mochila a cuestas, experiencias de vida, formación académica, luchas, también contradicciones, llevó adelante uno de los mayores emprendimientos para la construcción de una universidad necesaria en Costa Rica, basado en un profundo humanismo de base cristiana. Pues, afirmaba: "Dios le dio al hombre la inteligencia para que continuara participando en la incesante evolución creativa, según dice Teilhard de Chardin, la obra inconclusa de la creación" (Núñez, 1992, p. 189).

\section{Referencias}

Arauz, A., Arroyo, A., Azofeifa, I. F., Azofeifa, E., Acuña, J. R., Barahona, R., ... Urbina, J. (1968). Patio de Agua. Manifiesto democrático para una revolución social. Coronado, Costa Rica: Editorial Eloy Morúa Carrillo. Recuperado de http://guiascostarica.info/edel/book/patio-de-aguamanifiesto-democratico-para-una-revolucion-social// 
Araya, C. (1990). Las transformaciones de la educación superior estatal en la década de los 70. Revista de Ciencias Sociales, 49-50, 49-62.

Araya, C. (1994). La Universidad Nacional y la educación superior estatal en veinte años de historia (1973-1993). Heredia, Costa Rica: EUNA.

Arbeláez, Á. M. (entrevistadora). (s. f.). Autoridad de antigüedades de Israel \& Benjamín Núñez: El cura amigo de Israel, con Rodrigo Carreras, embajador de Costa Rica [Entrevista de radio]. Radio Sefarda.com. Programa Cosmos Israeli. Recuperado de http://www.radiosefarad. com/autoridad-de-antiguedades-de-israel-benjamin-nunez-el-cura-amigo-de-israelcon-rodrigo-carreras-embajador-de-costa-rica/

Arpini, A. M. (2015). Diversidad y reconocimiento: para una revisión del humanismo. Pico della Mirándola y Bartolomé de las Casas. En A. M. Arpini, (Coord.), El Humanismo, los humanismos. Ideas y prácticas revisadas desde nuestra América (pp. 31-46). Mendoza, Argentina: EDIUNC.

Aveiro, M. O. (2011). Darcy Ribeiro: Processos civilizatorios y universidad. Cuadernos Americanos, 2(136), 11-44. Recuperado de http://www.cialc.unam.mx/cuadamer/textos/ca136-11.pdf

Aveiro, M. O. (2013). Políticas académicas en dos pensadores latinoamericanos: Darcy Ribeiro y Arturo Andrés Roig. Roteiro, número especial, 89-108. Recuperado de http://editora. unoesc.edu.br/index.php/roteiro/article/view/2489/pdf

Aveiro, M. O. (2015a). Darcy Ribeiro: De la universidad connivente a la universidad necesaria en América Latina. En A. M. Arpini, (Coord.), El Humanismo, los humanismos. Ideas y prácticas revisadas desde nuestra América (pp. 265 - 275). Mendoza, Argentina: EDIUNC.

Aveiro, M. O. (2015b). La universidad inconclusa. De la ratio studiorum a la reforma universitaria en Mendoza (1973-1974). Mendoza, Argentina: EDIUNC.

Avila, M. C. (2015). Aportes para repensar el humanismo desde las obras de Hannah Arendt y Giorgio Agamben. En A. M. Arpini (Coord.), El Humanismo, los humanismos. Ideas y prácticas revisadas desde nuestra América (pp. 101-113). Mendoza, Argentina: EDIUNC.

Beorlegui, C. (2004). Historia del pensamiento filosófico latinoamericano. Una búsqueda incesante de la identidad. Bilbao: Deusto.

Bosch, J. (1971). El próximo paso: Dictadura con respaldo popular. Santo Domingo: Publicaciones Max.

Carreras, R. X. (s. f.). Reseña biográfica del Rev. Dr. Benjamín Núñez Vargas: Sacerdote, sindicalista, capellán, diplomático, académico y soñador. El espíritu del 48. Recuperado de http://www. elespiritudel48.org/docu/h020.htm 
doi: http://dx.doi.org/10.15359/ree.21-3.5

URL: http://www.una.ac.cr/educare

CORREO: educare@una.cr

Chase, A. (2013). Notas para una biografía: Padre Benjamín Núnez. Recuperado de http://www. prensalibre.cr/lpl/comentarios/81325-notas-para-una-biografia-padre-benjamin-nunez. $\underline{\text { html }}$

Contreras, G. (2008). Una lectura crítica de don José Figueres Ferrer. En torno a la guerra civil de 1948 y su papel en la Junta Fundadora de la Segunda República. Diálogos. Revista Electrónica de Historia, 9(1), 176-207. Recuperado de https://docs.google.com/viewerng/ viewer?url=https://revistas.ucr.ac.cr/index.php/dialogos/article/viewFile/6145/5849

Cuevas, R. (1995). El punto sobre la i. Políticas culturales en Costa Rica (1948-1990). San José, Costa Rica: Ministerio de Cultura, Juventud y Deportes de Costa Rica. Recuperado de http:// repositorio.una.ac.cr/bitstream/handle/11056/2627/recurso 722.pdf?sequence $=1$

Delgado, M. (Guionista y director). (8 de marzo de 2008). 1948, Rafael Ángel Calderón Guardia y José Figueres Ferrer (TV). En D. Delgado (Productor ejecutivo), 7 días, Canal 7. Recuperado de http://www.youtube.com/watch?v=P6QCYq7tZYY

Ferraro, J. (2009) La lucha contra el comunismo. De León XIII al Segundo Concilio Vaticano. México, UAM-Iztapalapa.

Figueres, J. (2000) Escritos de José Figueres Ferrer. Política, economia y relaciones internacionales. San José, Costa Rica: EUNED.

Kaufmann, C. (Dir.). Lijtmaer, N. M. y Mauri, R. C. (2008) Shules y ateneos. Huellas de la educación no formal judeorosarina (Del Wesser a la Web). Rosario: Laborde Editor.

La Prensa Libre. (23 de enero de 2015). Este sábado se celebran 100 años del nacimiento de Benjamín Núnez Vargas. Recuperado de http://www.laprensalibre.cr/Noticias/detalle/9780/152/ este-sabado-se-celebran-100-anos-del-nacimiento-de-benjamin-nunez-vargas

Molina, I. (agosto 2007-febrero, 2008). Educación y sociedad en Costa Rica: De 1821 al presente (una historia no autorizada). Diálogos. Revista Electrónica de Historia, 8(2), 151- 356. Recuperado de https://docs.google.com/viewerng/viewer?url=https://revistas.ucr.ac.cr/ index.php/dialogos/article/viewFile/18349/18539

Moro, T. (2003) Utopía. Buenos Aires: Editorial Losada.

Núñez, B. (1974). Hacia la universidad. Heredia: Universidad Nacional de Costa Rica.

Núñez, B. (1992). Del Volcán Irazú al Monte Sion. Heredia, Costa Rica: Editorial de la Universidad Nacional.

Núñez de Castro, I. (s. f.) La biofilosofía de Theilard de Chardin. Recuperado de http://www. upcomillas.es/webcorporativo/Centros/catedras/ctr/Documentos/BIOFILNUCASTRO.pdf 
Pablo Vl. Carta encíclica. Populorum progressio. (26 de marzo de 1967). Recuperada de http:// www.vatican.va/holy father/paul vi/encyclicals/documents/hf p-vi enc 26031967 populorum sp.html

Quesada, J. R. (2003). Estado y educación en Costa Rica. Del agotamiento del liberalismo al inicio del Estado interventor: 1914-1949 (Serie Cuadernos de Historia de las Instituciones en Costa Rica). San José, Costa Rica: Editorial de laUniversidad de Costa Rica. Recuperado de http:// sinabi.go.cr/Biblioteca\%20Digital/LIBROS\%20COMPLETOS/Quesada\%20Camacho\%20 Juan\%20Rafael/Estado\%20y\%20eduacion\%20en\%20Costa\%20Rica.pdf

Quesada, R. (1993) La Universidad Nacional: Del heredio-comunismo al heredio-narcisismo. ABRA, 14(19-20), 123-129. Recuperado de http://www.revistas.una.ac.cr/index.php/abra/ issue/view/401

Ramaglia, D. (2013-2016). Reconocimiento y diversidad. Para un humanismo crítico de América Latina en el siglo XX. Il etapa (Proyecto de investigación SECTPYP). Universidad Nacional del Cuyo. Facultad de Filosfía y Letras.

Ribeiro, D. (1973). La universidad nueva, un proyecto. Buenos Aires: Editorial Ciencia Nueva.

Rivera, L. M. (Elaboración del material legislativo) (2012). Asamblea Legislativa de Costa Rica fomenta igualdad de oportunidades en la educación superior estatal: Aprobación de la Ley de Creación de la Universidad Nacional, 15 de febrero de 1973. San José: Departamento de Servicios Parlamentarios.

Roig, A. A. (1998). La universidad hacia la democracia. Bases doctrinarias e históricas para la constitución de una pedagogía participativa. Mendoza, Argentina: EDIUNC.

Ruiz, Á. (2001). El destino de Costa Rica y la educación superior. El escenario histórico del país, la educación y el papel de la universidad. San José, Costa Rica: Editorial de la Universidad de Costa Rica. Recuperado de http://www.centroedumatematica.com/aruiz/libros/El\%20 Destino\%20de\%20Costa\%20Rica\%20y\%20la\%20Educacion\%20Superior.pdf

Tamayo y Salmorán, R. (1987). La universidad epopeya medieval. Notas para un estudio sobre el surgimiento de la universidad en el alto medievo. México: Universidad Nacional Autónoma de México.

UNA 40 Años. Educación superior para el bien común (14 de marzo, 2013). Campus 24(241).

Valerín, O. (28 de enero, 2010). Padre Benjamín Núñez Vargas. En Cápsula Herencias. Transmitido por Televisora de Costa Rica, Televica, Canal 7 [Archivo video youTube]. Recuperado de http://www.youtube.com/watch?v= Niv4VMujql 